可視化情報 Vol.19 Suppl. No2（1999年10月）

\title{
C202回転円筒内における固体粒子の 再分離シミュレーションの数值可視化
}

\author{
牛島省 ○ 田中伸和山本 亮介（電中研） \\ Numerical Visualization on Segregation of Granular Binary Mixture in Rotating Cylinder
}

Satoru Ushijima, Nobukazu Tanaka and Ryosuke Yamamoto

\begin{abstract}
A new parallel computational technique has been proposed for the mixing and segregation of granular mixture with multi-block grid system. In this technique, a three-dimensional computational volume is decomposed into multiple blocks which are represented by $3 \mathrm{D}$ body-fitted coordinates. The computations of the particle motions in the multiple blocks are executed simultaneously on the basis of the distinct element method (DEM). The possible particle contacts through the boundary shared by two blocks are detected by exchanging the particle positions included in the nearboundary volumes. Since the numerical visualization procedure is also treated as one of the parallel processes, it scarcely affects the efficiency of particle computations. The computational method was applied to the granular binary mixture in a horizontal rotating cylinder. As a result, it was shown that the segregation of the mixture is successfully predicted by the present technique.
\end{abstract}

Keywords : parallel computation, multi-block grid, segregation, DEM, numerical visualization

1.はじめに

粒径や比重などの物性値が均一でない粒子混合物 の混合あるいは偏析に関して, 近年数値解析手法を 用いた現象解明が精力的に進められている.特に，回 転円筒容器内の粉粒体混合物の偏析に関しては, 坂 本 [1]により, 離散要素法 (DEM) [2] を用いた数値 解析が行われ，粒子の空閒的な分布や運動特性に関 する考察がなされている.

DEMによる数值解析は，このように粉粒体の挙動 を把握するための有効な手法の一つであるが，これ をより広範な適用性を有する計算手法とするために は，(1) 多数の粒子を解析するための計算効率の向上, （2）複雑な境界形状一の適用性の抎大，(3) 粒子の分 布・運動状態を把握するための可視化機能の付加，な どをさらに検討することが必要であると考えられる. このため, 本報では, 計算対象領域を複数のブロック に分割して, 各ブロックの形状を 3 次元境界適合座 標系で表現することにより, 複雑な境界形状への適用 性を確保するとともに,ブロック内の粒子計算を並列 的に実行して計算効率の向上を図る手法を提案する. さらに，非定常計算過程で得られる粒子分布等の表 示を行う可視化プロセスを, 粒子計算のプロセスと 並列的に動作させることにより，粒子計算に負荷を与 えずに数值可視化処理を行うものとする.

本報では，この数值解析手法を用いて，回転円筒容
器内における粒径と密度の異なる 2 種類の固体粒子 から構成される粒子混合物の挙動を解析した. 実験 結果との比較から, 解析手法の妥当性を確認すると ともに，並列化による計算効率や可視化プロセスの 動作状況等もあわせて検討した。

\section{2. 数值解析手法}

\section{$2.1 \mathrm{DEM}$ を利用した並列粒子計算}

粒子計算の対象となる 3 次元の領域は, ユーザが 設定した適当な断面により, 複数のブロック領域に分 割される.この分割により, 計算領域は比較的単純な 形状のブロックの集合として表され, 各ブロックの形 状は 3 次元境界適合座標系により表現される.これら の手順は, 著者らが流体解析のために提案したマル チブロック・並列計算手法 [3] と同様である.

各ブロック内の粒子計算は, ブロック数と同数起動 されるスレーブプロセスにより行われ，スレーブプロ セス間のデータ通信は単一のマスタープロセスによ り管理される.さらに, 計算結果を可視化する可視化 プロセスが 1 つ起動され, 全スレーブプロセスから 粒子の情報を受信して粒子計算と並列的に GWS 上 で描画処理を行う. Fig. 1 は, 粒子計算の手順とこ れらのプロセスの関係を概略的に示したものである. この図では，2つのスレーブプロセスが破線で囲まれ た部分として示されており, グレーに着色された部分 は, マスタープロセスと可視化プロセス, それらと通 
信を行う処理を表している。

スレーブプロセスでは，Fig. 1に示されるように， ブロック内に含まれる粒子運動が DEMに基づいて行 われる. 個々の粒子の運動は, 3 次元場の並進および 回転運動に対する支配方程式を離散化して非定常的 に計算する．粒子間および粒子と境界面との間で発 生する接触力は, DEM で一般に用いられるバネーダ シュポットモデルにより評価する. また, 粒子に作用 する気相の流体力としては, 並進運動の支配方程式 中に抗力, 揚力を, また回転運動に対しては, 粘性に より生ずる減衰力を考慮している.

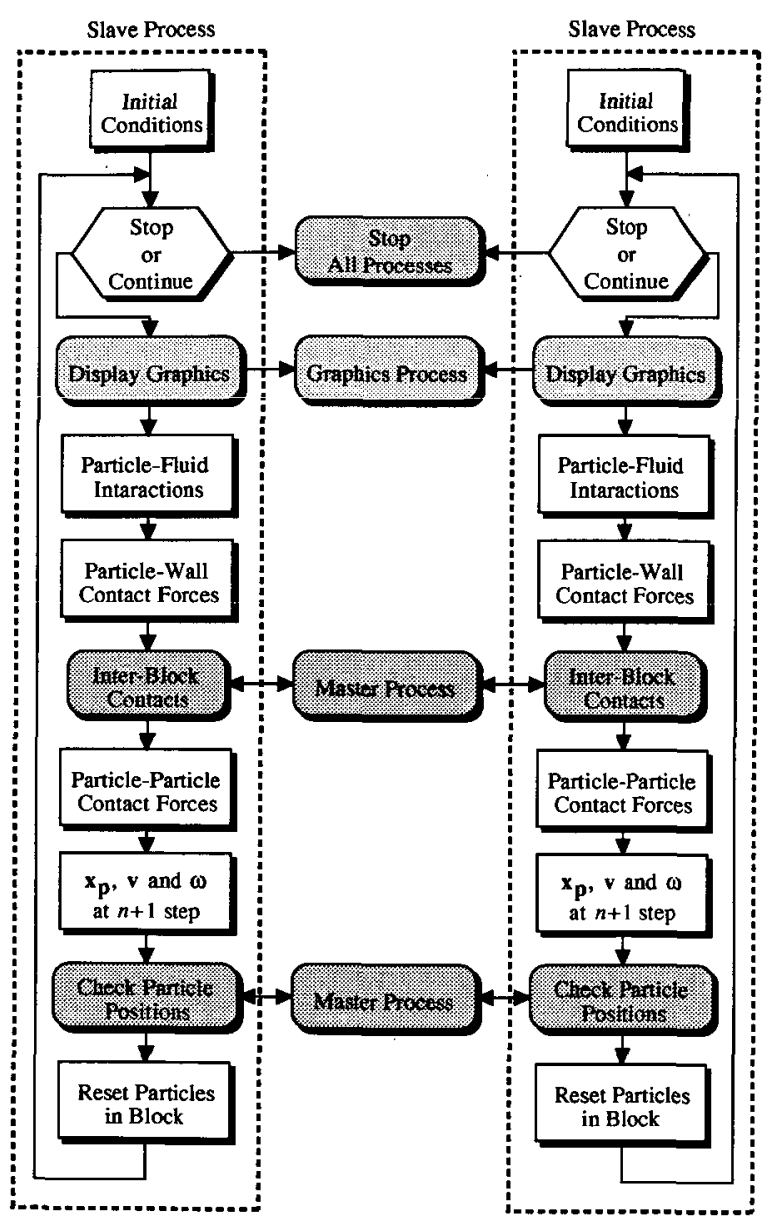

Fig. 1 Flow Chart of Parallel Computation

\section{2 粒子計算におけるプロセス間通信}

マルチブロック環境における粒子計算では，(1) ブ ロックどうしが接続する断面 (共有境界面)を介して 接触する, 異なるブロックに属する粒子の間に働く接 触力, および, (2) 新しい時間ステップに発生する他 のブロックへの粒子の移動, の 2 つを適切に取り扱 うことが必要となる。

このうち, (1)に対しては, Fig. 2に示すように, 共有境界面付近に交換ボリュームを設定し，その内部
に含まれる粒子の情報をマスタープロセスを介して ブロック間で交換するものとした. 各ブロックでは, 交換ボリュームを共有境界面の外側に付加した状態 で粒子の接触力の評価が行われるため, マルチブロッ ク環境においても連続的な接触判定が可能となる. 次 に，(2)のブロック閒の粒子移動に関しては，まず共 有境界面からブロック外部一移動した粒子の情報を マスタープロセスへ伝達するとともに自ブロックか らその粒子を削除する．マスタープロセスは，該当す る粒子の情報を移動先のブロックへ伝達し，移動先の ブロックは領域内に粒子を追加して計算を進める.

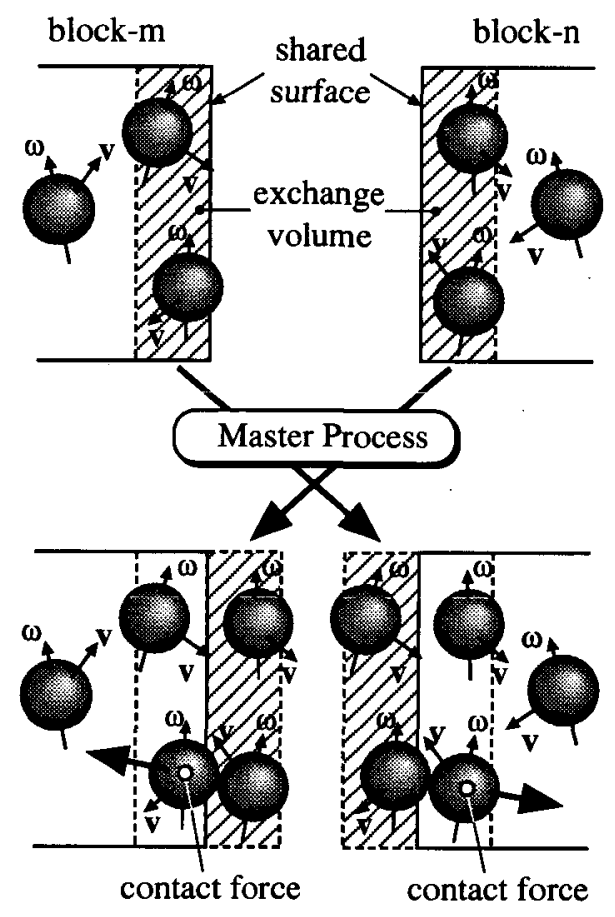

Fig. 2 Particle Contact between Sheared Boundary

\section{3 計算機器の構成と可視化プロセス}

粒子混合物の並列計算に利用した計算機の構成 をFig. 3 に示す。ここでは, 100BaseT でネットワー ク接続された PC クラスタに MPI [4] 準拠の LAM (http://www.mpi.nd.edu/lam/) をインストールして 並列計算環境を設定した. Fig. 3 に示されるように， 可視化プロセスは GWS(SGI Octane) 上で実行され， 所定の計算ステップごとに全スレーブプロセスから 粒子位置や粒径などの情報を受信してそれらの描画 を行う．スレーブプロセスは通信終了後，直ちに粒子 計算を続行するため, 次回の可視化プロセスとの通 信までに描画が終了するように通信頻度が設定され ていれば，GWS 上での可視化処理は粒子計算に負荷 を及ぼさない。 


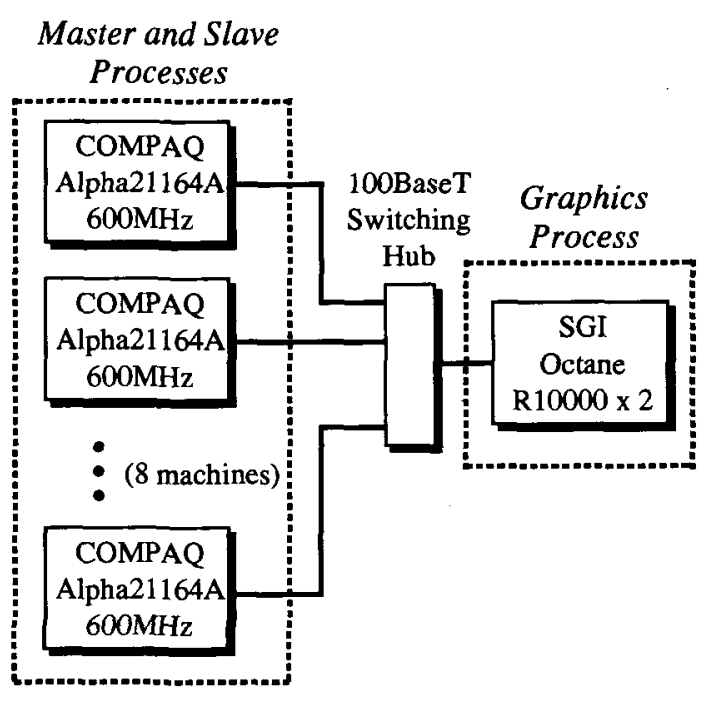

Fig. 3 Configuration of GWS and PC Cluster

\section{3. 解析手法の適用性}

\section{1 計算条件}

中心軸が水平に設置された円筒容器内において, 静 止状態にある粒子混合物に回転運動を加えた場合の 非定常計算を行った. Fig. 4 に円筒容器と座標系を 示す.

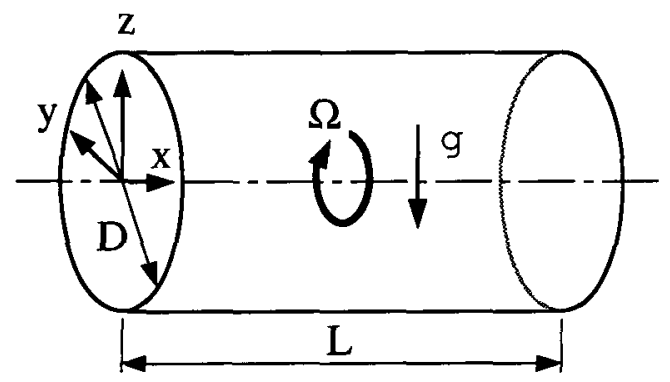

Fig. 4 Rotating Horizontal Cylinder

円筒容器は直径 $D$ が $50 \mathrm{~mm}$, 軸方向長さ $L$ が $90 \mathrm{~mm}$ で, 毎秒 0.93 回転の速度で円筒軸を中心に回 転する. 座標系は, 軸方向に $\mathrm{x}$ 軸, 鉛直上方に $\mathrm{z}$ 軸を とる. マルチブロック計算では, 円筒容器を軸方向に 同じ長さを持つ 4 つのブロックに分割し，Fig. 3 に 示される計算機のうち 5 台の PCに 1 つのマスター プロセスと 4 つのスレーブプロセスを割り当てた.

利用した固体粒子は, 粒径 $6.4 \mathrm{~mm}$, 密度 $1.14 \mathrm{~g} / \mathrm{cm}^{3}$ の粒子 (N6 粒子) と粒径 $3.3 \mathrm{~mm}$, 密度 $3.60 \mathrm{~g} / \mathrm{cm}^{3}$ の 粒子 (A3 粒子) の 2 種類である. 粒子混合物は, 50 個 の N6 粒子と 250 個の $\mathrm{A} 3$ 粒子から構成されるものと した，計算では，N6 および A3 粒子は，同一の摩擦 係数, 反発係数およびバネ定数を有するものとし, 值 はそれぞれ $0.4 ， 0.75$ および $5.0 \times 10^{4} \mathrm{~N} / \mathrm{m}$ とした。

粒子混合物は，最初に円筒容器内にランダムに配
置し，それらが底部に自由落下して十分に時閒が経 過した静止状態を計算の初期条件とした. 1 ステップ の非定常計算の時間間隔 $\Delta t$ は, $1.0 \times 10^{-5} \mathrm{sec}$ とし, 可視化プロセスとの通信, すなわち数値可視化処理は 粒子計算 100 ステップに対し 1 回実行するものとし た.この描画頻度により，連続的な粒子分布の遷移を 把握できるが，GWS 上での計算負荷を調べた結果， 1 回の描画処理は次回の通信開始までに十分な余裕を 持って終了しているので, 粒子計算に負荷を与えてい ないことが確認できた。

\section{2 並列処理による計算効率}

上記の粒子混合物の計算に先立ち，並列化による 計算効率を把挃するため，均一粒径 $(D=1 \mathrm{~mm})$ の 粒子のみを利用して, 円筒容器を 1 (シングルブロッ ク), 2 および 4 ブロックとしたときの計算時間を比 較した。この計算では，粒子数を 500 から 100,000ま で変化させ， 1,000 ステップの計算に要する計算時間 を計測した．粒子の接触判定を効率良く行うためのセ ル分割を利用した結果，いずれの計算においても粒子 数と計算時間は線形に近い関係があることを確認し た.また，速度向上比 (同一粒子数のシシングルブロッ クの計算時間を除した値) は，粒子数が約 30,000 以 上になるとほぼ一定となり，その值は 2 ブロック計算 で約 $1.8 ， 4$ ブロック計算で約 2.8 となり，並列化に より計算効率が向上することが確認された。なお，粒 径が均一でない場合には，接触判定のためのセル分 割を最大粒径に合わせる必要が生ずるため，並列計 算による速度向上比はさらに増加すると考えられる.

\section{3 円筒容器内の粒子の分布}

3.1 で述べた粒子混合物の数値解析の結果，円筒容 器の回転開始直後から粒子の分離が始まり，十分な時 間が経過すると Fig. 5 に示すように，A3 粒子は円 筒側面に沿って上昇するかたちで集合し，その背後に N6 粒子が取り残される状態で偏析した．また，軸方 向には, 中央部付近に A3 粒子が分布し, 円筒容器両 端部付近にN6 粒子が集まる傾向が見られた。

この数值計算と同様の条件において，ナイロン粒子 とアルミナ粒子 (それぞれ N6 およびA3 粒子に相当) を使用して得られた実験結果をFig. 6 に示す.この 実験結果は, 透明アクリル円筒容器内に上記の 2 種 類の粒子を入れ，回転運動を加えたときに撮影したビ デオ画像から得られたものである．実験においても， 円筒容器中央部では，A3 粒子は上昇する側，N6 粒 子はその背後側に分布する.一方, 円筒容器の両端部 近傍では，これと異なり，N6 粒子は，円筒容器の両 端面と接触して回転とともに比較的高い位置まで移 動する状況が観察された. Fig. 5 およびFig. 6 の結 
果は, 両者ともある時刻の粒子分布をとらえたスナッ フショットであるが，どちらも回転開始後十分に時間 が経過した時点のほぼ典型的な分布であり，両者は同 様の傾向を示している.

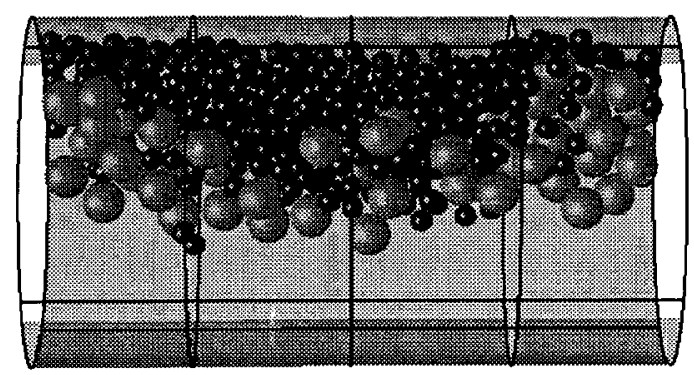

Fig. 5 Snapshot of Calculated Particle Distribution Captured in Visualization Process

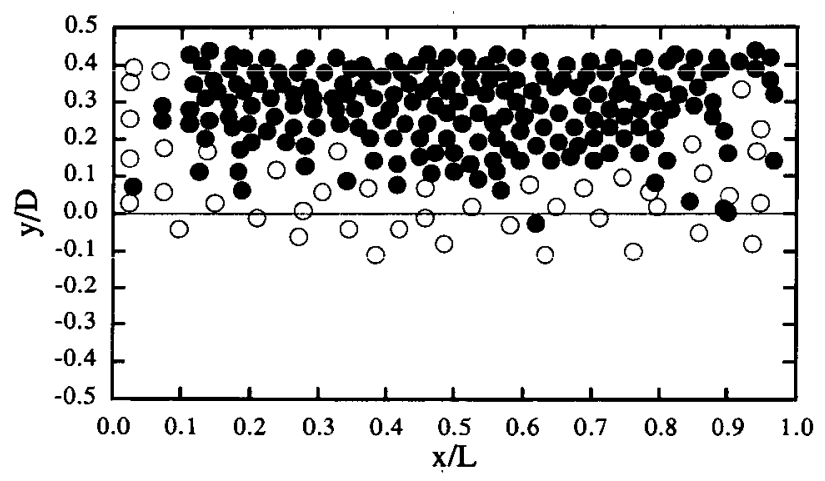

Fig. 6 Snapshot of Particles in Experiments $=\mathrm{A} 3$ particle $; \mathrm{O}=\mathrm{N} 6$ particle)

一方, 計算結果から得られた粒子の平均的な分布 をFig. 7 とFig. 8 に示す. この結果は, 粒子分布が 安定した後, 約 20 秒間にわたる粒子位置を 1,000 ス テップごとに $x-y$ 平面上に投影し, $2.5 \mathrm{~mm} \times 2.5 \mathrm{~mm}$ の大きさのセル分割を行って, セル内に含まれる粒 子数を $\mathrm{A} 3$ および $\mathrm{N} 6$ 粒子ごとに正規化したものであ る.この結果から, 粒径が比較的大きい $\mathrm{N} 6$ 粒子は, 主として円筒容器両端部付近に安定的に存在してお り, 軸方向中心付近 $(x / L=0.5)$ に向かうにつれ, 分 布位置が $-y$ 方向に向かう傾向を示している. 一方, Fig. 8 に示した A3 粒子に対する結果では, A3 粒子 は軸方向中心付近に安定的に存在し, 両端に向かう につれて分布位置が $+y$ 方向に向から傾向を示寸.上 記の結果のうち, 特に大粒径の粒子が円筒容器の両 端付近に集中するのは, Wightman ら [5]の実験結果 でも認められている一般的な傾向であり，本報の計算 でもこれと同様の現象を再現し得ることが示された.

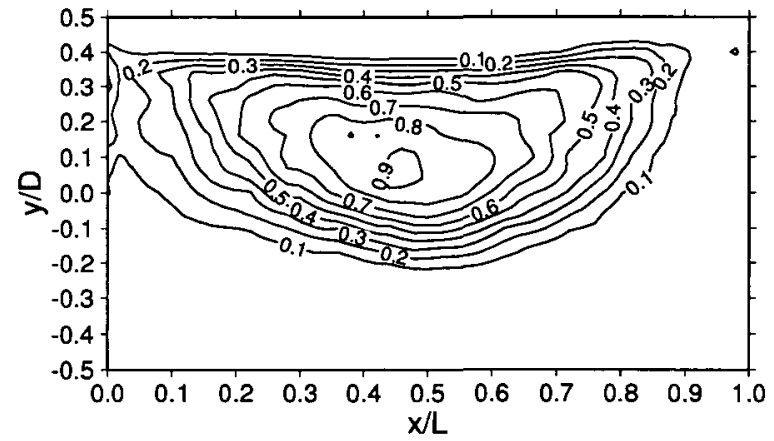

Fig. 7 Averaged Distribution of N6 Particles

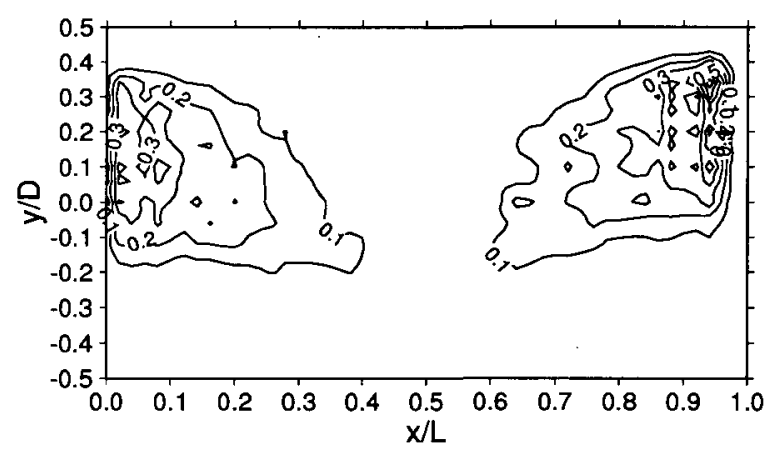

Fig. 8 Averaged Distribution of A3 Particles

4. おわりに

本報では，DEMによる粒子計算法に対してマルチ ブロック・並列計算法を適用することにより, 計算効 率を向上させると同時に, 並列的に害行される数値 可視化機能の付加を行った. 本計算手法により回転円 筒容器内における粒子混合物の非定常計算を行った 結果, 妥当な粒子の分布状況が得られることが示さ れた.

\section{参考文献}

[1] 坂本昇一. 回転ドラム内における粒体混合物の軸 方向偏析一離散要素法による数値解析一. 粉体工 学会誌, Vol. 35, pp. 583-513, 1998.

[2] P. A. Cundall and O. D. L. Strack. A discrete numerical model for granular assemblies. Geotechnique, Vol. 29, No. 1, pp. 47-65, 1979.

[3] S. Ushijima, N. Yoneyama and N. Tanaka. Multiblock-parallel computations of 3D flows in complicated-shaped hydraulics structures. Proc. 7th Int. Symp. on Flow Modeling and Turbulence Measurements, pp. 347-354, 1998.

[4] W. Gropp, E. Lusk and A. Skjellum. Using MPI. The MIT Press, 1994.

[5] C. Wightman and F. J. Muzzio. Mixing of granular material in a drum mixer undergoing rotational and rocking motions, ii. segregating particles. Powder Technology, Vol. 98, pp. 125-134, 1998. 